\title{
A Novel Signaling Pathway That Modulates Inflammatory Pain
}

\author{
Wiebke Kallenborn-Gerhardt ${ }^{1,2}$ and Achim Schmidtko ${ }^{1}$ \\ ${ }^{1}$ Pharmazentrum Frankfurt/ZAFES, Institut für Klinische Pharmakologie, and ${ }^{2}$ Graduate Program of the Collaborative Research Center 815 , Klinikum der \\ Goethe-Universität, 60590 Frankfurt am Main, Germany \\ Review of Zhang et al.
}

Painful and tissue-damaging stimuli are sensed by small- and medium-diameter primary afferent neurons located in the dorsal root ganglia (DRG) and trigeminal ganglia. These neurons further communicate the pain signal to the CNS, leading to the conscious awareness of pain. Previous research has identified multiple intracellular signaling pathways in DRG neurons that are activated in response to tissue damage and inflammation or lesions to the nervous system. Most of the identified signaling cascades sensitize the DRG neurons during persistent inflammatory or neuropathic pain. For example, activation of kinases, including protein kinase $\mathrm{C}$ (PKC), protein kinase A, and extracellular regulated kinase, and subsequent phosphorylation of downstream effectors, such as transient receptor potential and voltagegated sodium channels, reduce the activation threshold of DRG neurons, producing hypersensitivity (Woolf and Ma, 2007).

Perceived pain intensity is also negatively regulated by pain modulatory systems. In addition to brainstem descending pathways and spinal inhibitory interneurons that inhibit nociceptive processing,

Received 0ct. 8, 2010; revised Nov. 8, 2010; accepted Nov. 10, 2010.

This work was supported by the Deutsche Forschungsgemeinschaft (SFB815-A14).

Correspondence should be addressed to Wiebke Kallenborn-Gerhardt, Pharmazentrum Frankfurt/ZAFES, Institut für Klinische Pharmakologie, Klinikum der Goethe-Universität, Theodor-Stern-Kai 7, 60590 Frankfurt am Main, Germany. E-mail: kallenborn@med.uni-frankfurt.de. DOI:10.1523/JNEUROSCI.5285-10.2011

Copyright $\odot 2011$ the authors $\quad 0270-6474 / 11 / 310798-03 \$ 15.00 / 0$ accumulating evidence suggests that inhibitory signaling pathways within DRG neurons limit their excitability. A recent study published in The Journal of Neuroscience (Zhang et al., 2010) describes a previously unknown signaling pathway of pain control in DRG neurons.

In a microarray screen for neuropeptides and their receptors, Zhang et al. (2010) found that B-type natriuretic peptide (BNP) and its receptor, natriuretic peptide receptor-A (NPR-A), are expressed in DRG neurons. Expression of both BNP and NPR-A was upregulated in small DRG neurons upon noxious hindpaw stimulation by complete Freund's adjuvant (CFA), an agent that induces tissue inflammation and pain sensitization, suggesting that BNP/ NPR-A signaling might contribute to CFAinduced hypersensitivity.

Zhang et al. (2010) investigated whether BNP/NPR-A signaling modulates the activity of DRG neurons. Using whole-cell patch-clamp recordings in freshly dissociated small DRG neurons, they found, unexpectedly, that BNP reduced DRG neuron excitability. Moreover, this inhibitory effect occurred only in the presence of glutamate; BNP alone failed to affect excitability.

Because the receptor NPR-A is a guanylyl cyclase that produces cGMP upon activation by BNP, Zhang et al. (2010) hypothesized that cGMP-dependent protein kinase I (PKG-I) and large-conductance voltage- and $\mathrm{Ca}^{2+}$-activated $\mathrm{K}^{+}$channels $\left(\mathrm{BK}_{\mathrm{Ca}}\right.$ channels) might mediate the activ- ity-dependent inhibitory effect of BNP This hypothesis is plausible because earlier reports indicated that both PKG-I and $\mathrm{BK}_{\mathrm{Ca}}$ channels are expressed in small DRG neurons, activation of PKG-I may lead to phosphorylation of $\mathrm{BK}_{\mathrm{Ca}}$ channels and thus increase their open probability, and open $\mathrm{BK}_{\mathrm{Ca}}$ channels contribute to the fast afterhyperpolarization that limits further spiking after an action potential (Qian et al., 1996; Zhou et al., 2010). Indeed, Zhang et al. (2010) demonstrated that the inhibitory effect of BNP on DRG neuron excitability was attenuated by pretreatment with a PKG-I inhibitor or a $\mathrm{BK}_{\mathrm{Ca}}$ channel blocker. These data indicate that $\mathrm{BNP} / \mathrm{NPR}-\mathrm{A} / \mathrm{cGMP}$ signaling may inhibit the activity of small DRG neurons through activation of PKG-I and subsequent phosphorylation of $\mathrm{BK}_{\mathrm{Ca}}$ channels (Fig. 1).

$\mathrm{BK}_{\mathrm{Ca}}$ channels are regulated by both intracellular $\mathrm{Ca}^{2+}$ and membrane potential. Hence, the observation that BNP exerts its inhibitory effect only in the presence of extracellular glutamate might be explained by the requirement of activation of glutamate receptors that further increases $\mathrm{Ca}^{2+}$ influx into DRG neurons during nociceptive processing. This assumption was assessed by Zhang et al. (2010) using whole-cell voltage-clamp experiments in small DRG neurons. In fact, they demonstrated that application of BNP together with glutamate to the extracellular solution induced a robust increase in $\mathrm{BK}_{\mathrm{Ca}}$ current density at a membrane 


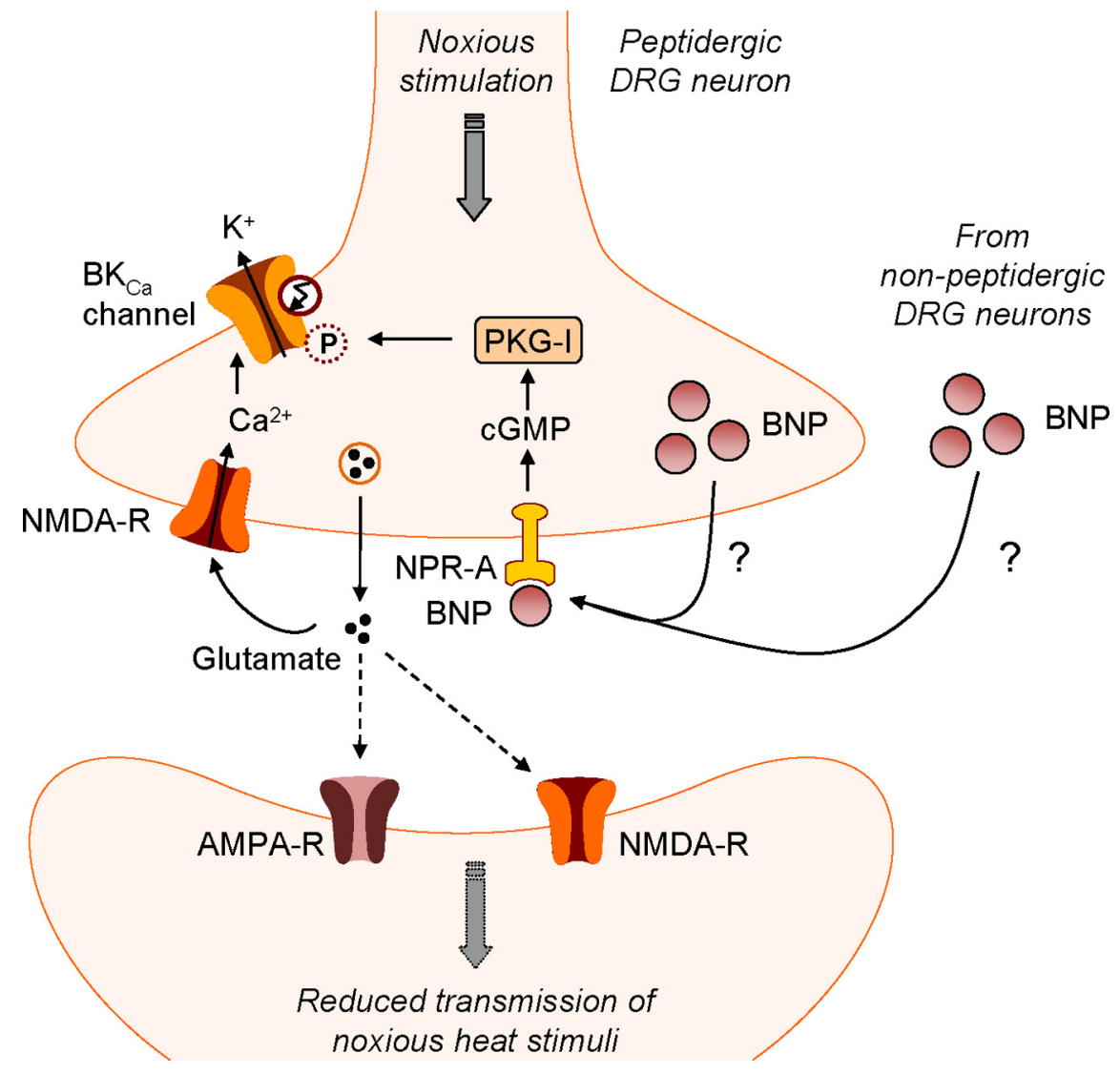

Figure 1. $\quad B N P / N P R-A / P K G-I / B_{C a}$ channel signaling in small primary afferent neurons during nociceptive processing (Zhang et al., 2010). NPR-A activation by BNP increases intracellular cGMP levels, leading to the activation of PKG-I and subsequent phosphorylation of $\mathrm{BK}_{\mathrm{Ca}}$ channels. Activation of this signaling pathway is restricted to peptidergic DRG neurons. It results in reduced transmission of noxious heat stimuli in the presence of extracellular glutamate that increases intracellular $\mathrm{Ca}^{2+}$. How BNP is released from primary afferent neurons remains to be elucidated.

potential of $-15 \mathrm{mV}$, which is approximately the voltage threshold for small DRG neurons to arise an all-or-none action potential. The authors calculated that the outward $\mathrm{K}^{+}$current generated by BNP plus glutamate was big enough to neutralize the inward $\mathrm{Na}^{+}$current at -15 $\mathrm{mV}$ and, therefore, to inhibit the neuronal firing. In contrast, bath application of BNP or glutamate alone generated an only moderate increase in $\mathrm{BK}_{\mathrm{Ca}}$ current density that was not sufficient to suppress the generation of action potentials.

Zhang et al. (2010) demonstrated that $\mathrm{BNP}$ and $\mathrm{BK}_{\mathrm{Ca}}$ channels are expressed in most small DRG neurons, including both peptidergic and nonpeptidergic neurons, as was previously shown for PKG-I (Qian et al., 1996). NPR-A, in contrast, was expressed almost exclusively in small peptidergic DRG neurons, suggesting that a complete signaling pathway of BNP, NPR-A, PKG-I, and $\mathrm{BK}_{\mathrm{Ca}}$ channels is only present in these neurons. This subset of DRG neurons transmits noxious thermal, but not mechanical, stimuli (Cavanaugh et al., 2009), indicating that BNP might selectively inhibit thermal hyperalgesia.

Zhang et al. (2010) confirmed the functional role of BNP in nociceptive processing in rat models of persistent pain. Consistent with the electrophysiological recordings cited above, CFA-induced thermal hyperalgesia was attenuated by intrathecal BNP treatment, and the recovery from thermal hyperalgesia was reversed by intrathecal injection of BNP antibodies. As expected from the absence of a complete BNP/NPR-A/cGMP/PKG-I/BK ${ }_{\mathrm{Ca}}$ channel signaling pathway in nonpeptidergic DRG neurons (Fig. 1), CFA-induced mechanical hyperalgesia was not affected by BNP treatment. Furthermore, intrathecal pretreatment with BNP reduced nocifensive paw flinching behavior after injection of formalin into a hindpaw. Notably, this effect was reversed by a $\mathrm{BK}_{\mathrm{Ca}}$ channel blocker or a PKG-I inhibitor, confirming the involvement of PKG-I and $\mathrm{BK}_{\mathrm{Ca}}$ channels in nociceptive BNP signaling.

The work presented by Zhang et al. (2010) introduces a novel endogenous mechanism for controlling pain processing in DRG neurons. However, several questions remain to be addressed in future studies. For example, how is BNP is released from DRG neurons during persistent pain? Because the ligand binding domain of NPR-A is located extracellularly, BNP can activate NPR-A only after being secreted into the extracellular space. It is, however, unclear whether BNP is stored in DRG neurons and released in an activity-dependent manner, similar to peptidergic neurotransmitters, or whether its release is regulated by gene expression and mainly depends on its synthesis. Of note, in the cardiac atrium, BNP is stored in granules and is secreted in response to increased intravascular volume, whereas in cardiac ventricles, BNP is not stored in granules but rather transcribed as needed and immediately released in response to cardiac stress states (Potter et al., 2009).

Another open question is how the BNP signal is terminated. In general, natriuretic peptides are cleared from the circulation by natriuretic peptide-receptor $\mathrm{C}$ (NPR-C) through receptor-mediated internalization and degradation (Potter et al., 2009). Interestingly, NPR-C mRNA has been detected in DRGs of mouse embryos (DiCicco-Bloom et al., 2004). Therefore, if NPR-C also terminates BNP signaling in DRG neurons, inhibition of NPR-C might be a novel analgesic strategy. Furthermore, phosphorylation and dephosphorylation of NPR-A represent an important mechanism of NPR-A regulation. Whereas dephosphorylation of the protein occurs early during ligand binding and positively contributes to the activation process, phosphorylation by PKC decreases NPR-A activity (Potter et al., 2009), suggesting that a tight regulation of NPR-A activity might also occur during nociceptive processing.

Particular attention should be paid to the exact role of PKG-I in pain processing. In contrast to the inhibitory function of PKG-I described by Zhang et al. (2010), earlier reports point to a mainly facilitating function of PKG-I in DRG neurons during inflammatory pain. For example, intrathecal injection of PKG-I inhibitors led to a reduction of nocifensive pawflinching behavior after formalin injection into a hindpaw (Tao et al., 2000). Even though the majority of small DRG neurons seem to express both PKG-I and $\mathrm{BK}_{\mathrm{Ca}}$ channels, targets different from $\mathrm{BK}_{\mathrm{Ca}}$ channels are likely to be phosphorylated by PKG-I as well. It is important to note that specific subcellular targeting of PKG-I is required for phosphorylation of 
certain substrates and associated effects (Francis et al., 2005). In particular, the $\mathrm{N}$-terminal leucine zipper motif of PKG-I can target the enzyme to selective proteins and subcellular compartments. Furthermore, cGMP-dependent protein kinaseinteracting proteins that localize PKG-I to certain microdomains of the cell and PKG-I relocation among cellular compartments in response to changes in cGMP levels have been reported (Francis et al., 2010). Importantly, PKG-I translocation within the cell increases after enzyme activation (Francis et al., 2010). Hence, it is conceivable that PKG-I, depending on its microcellular distribution and interaction with selective target proteins in DRG neurons, can either inhibit or facilitate inflammatory pain.

Finally, another important question inspired by the study reviewed here concerns a potential role of the BNP/NPR-A/ cGMP/PKG-I/BK $\mathrm{Ca}_{\mathrm{C}}$ channel signaling pathway during neuropathic pain. Studies with intrathecally injected $\mathrm{BK}_{\mathrm{Ca}}$ channel modulators suggest that $\mathrm{BK}_{\mathrm{Ca}}$ channels control the sensory input after peripheral nerve injury (Chen et al., 2009). It could therefore be valuable to investigate whether BNP and NPR-A expression is also upregulated after nerve injury, and whether
BNP also inhibits neuropathic pain behavior by modulating $\mathrm{BK}_{\mathrm{Ca}}$ channels through PKG-I activation.

Altogether, the work presented by Zhang et al. (2010) gives important insights into a novel endogenous inhibitory signaling pathway during inflammatory pain. The questions discussed above would be worth addressing in further studies to help determine whether the inhibitory role of BNP in nociceptive processing could serve as a new approach for pain therapy in future.

\section{References}

Cavanaugh DJ, Lee H, Lo L, Shields SD, Zylka MJ, Basbaum AI, Anderson DJ (2009) Distinct subsets of unmyelinated primary sensory fibers mediate behavioral responses to noxious thermal and mechanical stimuli. Proc Natl Acad Sci U S A 106:9075-9080.

Chen SR, Cai YQ, Pan HL (2009) Plasticity and emerging role of BKCa channels in nociceptive control in neuropathic pain. J Neurochem 110:352-362.

DiCicco-Bloom E, Lelièvre $\mathrm{V}$, Zhou X, Rodriguez W, Tam J, Waschek JA (2004) Embryonic expression and multifunctional actions of the natriuretic peptides and receptors in the developing nervous system. Dev Biol 271:161175.

Francis SH, Blount MA, Zoraghi R, Corbin JD (2005) Molecular properties of mammalian proteins that interact with cGMP: protein ki- nases, cation channels, phosphodiesterases, and multi-drug anion transporters. Front Biosci 10:2097-2117.

Francis SH, Busch JL, Corbin JD, Sibley D (2010) cGMP-dependent protein kinases and cGMP phosphodiesterases in nitric oxide and cGMP action. Pharmacol Rev 62:525-563.

Potter LR, Yoder AR, Flora DR, Antos LK, Dickey DM (2009) Natriuretic peptides: their structures, receptors, physiologic functions and therapeutic applications. Handb Exp Pharmacol 191:341-366.

Qian Y, Chao DS, Santillano DR, Cornwell TL, Nairn AC, Greengard P, Lincoln TM, Bredt DS (1996) cGMP-dependent protein kinase in dorsal root ganglion: relationship with nitric oxide synthase and nociceptive neurons. J Neurosci 16:3130-3138.

Tao YX, Hassan A, Haddad E, Johns RA (2000) Expression and action of cyclic GMP-dependent protein kinase Ialpha in inflammatory hyperalgesia in rat spinal cord. Neuroscience 95:525533.

Woolf CJ, Ma Q (2007) Nociceptors-noxious stimulus detectors. Neuron 55:353-364.

Zhang FX, Liu XJ, Gong LQ, Yao JR, Li KC, Li ZY, Lin LB, Lu YJ, Xiao HS, Bao L, Zhang XH, Zhang X (2010) Inhibition of inflammatory pain by activating B-type natriuretic peptide signal pathway in nociceptive sensory neurons. J Neurosci 30:10927-10938.

Zhou XB, Wulfsen I, Utku E, Sausbier U, Sausbier M, Wieland T, Ruth P, Korth M (2010) Dual role of protein kinase $\mathrm{C}$ on $\mathrm{BK}$ channel regulation. Proc Natl Acad Sci U S A 107:80058010. 